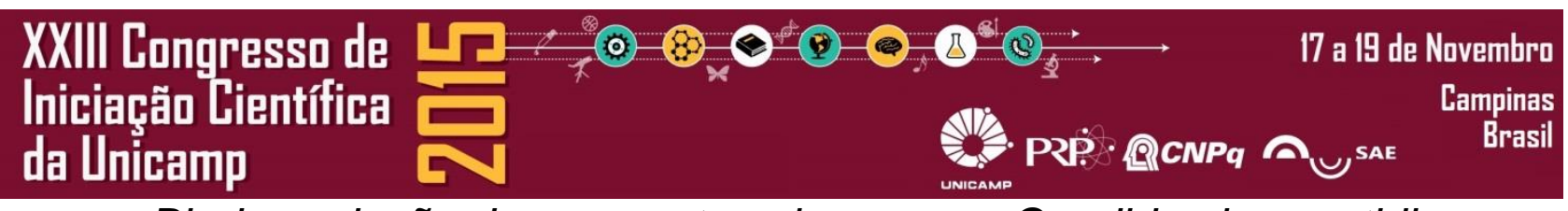

\title{
Biodegradação de compostos oleosos por Candida viswanathii
}

Gabriel L. Ribeiro (IC); Cassiana Maria Reganhan Coneglian (Orientadora

\section{Resumo}

O aumento da frota de veículos automotivos no Brasil e no mundo levou ao grande consumo de óleos bubrificantes e quando estes são descartados na água ou no solo de forma inadequada, os impactos ambientais podem ser severos. A microbiota do solo tem grande papel na biodegradação de substâncias naturais e antropogênicas, sendo as principais responsáveis pela recuperação de solo impactado. Neste trabalho avaliou-se a biodegradação do óleo de cozinha usado e do óleo diesel no solo, mediante a adição de Candida viswanathii, utilizando-se o respirômetro de Bartha e Pramer, metodologia que verifica a produção de $\mathrm{CO}_{2}$ gerado pelo processo da biodegradação microbiana no solo. Os resultados obtidos indicaram grande potencial da levedura na degradação dos compostos analisados.

Palavras-Chaves: óleo lubrificante, respirometria, Candida viswanathii.

\section{Introdução}

Segundo a Associação Brasileira das Indústrias de Óleos Vegetais (ABIOVE), apenas no estado de São Paulo são consumidos anualmente 242 milhões de litros de óleo e no Brasil são utilizados cerca de 3 bilhões de litros de óleo vegetal ao ano. Com base na legislação vigente, CONAMA $357 / 2005$, o artigo 34 estabelece o limite máximo de lançamento em corpo hídrico de $50 \mathrm{mg} / \mathrm{L}$; o Decreto Estadual 8468/76 no artigo 18 estabelece o limite legal de $100 \mathrm{mg} / \mathrm{L}$. A literatura afirma que aproximadamente 1 litro de óleo poluiu 20.000 litros de água.

Diante do grande consumo de óleos lubrificantes, tendo em vista o número elevado de veículos automotivos no Brasil e no mundo, e o grande consumo de óleo vegetal de uso culinário e o seus descartes incorretos, torna-se necessário o estudo da biodegradação destes compostos, visando a aplicação de medidas mitigadoras e melhoria da qualidade ambiental.

\section{Resultados e Discussão}

Realizou-se a biodegradação no solo de óleos lubrificantes e óleo de cozinha usado mediante a quantificação de $\mathrm{CO}_{2}$ pelo método de respirometria de Bartha de acordo com ABNT (1999). Após os ensaios de respirometria realizou-se a quantificação de bactérias e fungos do solo, avaliados em Unidades Formadoras de Colônia por grama de solo (UFC/g).

De acordo com os resultados obtidos verificou-se que a inoculação da levedura Candida viswanathii otimizou $o$ processo de biodegradação dos compostos no solo, verificando pela maior geração de $\mathrm{CO}_{2}$ nos respirômetros onde inoculouse a levedura.

A Figura 1 expressa os resultados da geração acumulada de $\mathrm{CO}_{2}$ durante o período de 32 dias.

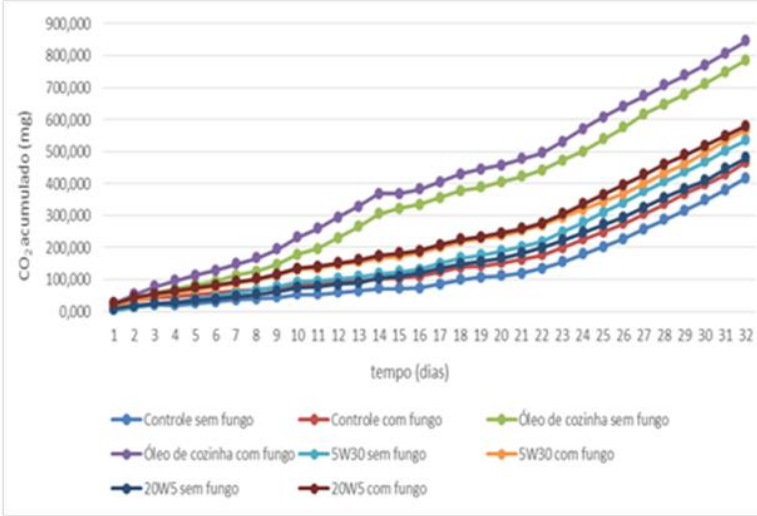

FIGURA 1. Resultados da geração de $\mathrm{CO}_{2}$ acumulada durante 32 dias de biodegradação de compostos oleosos no solo.

\section{Conclusões}

Concluir-se neste trabalho que a inoculação da levedura otimizou a processo de biodegradação dos compostos oleosos no solo, visto que Candida viswanathii, produz lípases, enzima que transforma lipídeos (gorduras) em ácidos graxos e glycerol, contribuindo para remediação de solo contaminado com estes compostos.

\section{Agradecimentos}

A Deus por ter me dado saúde e força para superar as dificuldades e fornecer capacidade para realização do trabalho, ao técnico do Laboratório de Saneamento Ambiental, Gilberto de Almeida pela paciência e por auxiliar na realização, a orientadora $\operatorname{Prof}^{\mathrm{a}} \mathrm{Dr}^{\mathrm{a}}$ Cassiana M.R. Coneglian pelo aprendizado e ensinamentos e a Universidade Estadual de Campinas - Faculdade de Tecnologia por fornecer as instalações para a conclusão.

\footnotetext{
${ }^{1}$ ABNT. Associação de Normas Técnicas. 1999. Resíduos no solo. Determinação da biodegradação pelo método respirometrico. ${ }^{2} \mathrm{APHA}$ - American Public Health Association. Standard methods for the examination of water and wastewater, $21^{\text {th }} \mathrm{ed}$. Washington, APHA, AWWA, EFA. 2012
} 